\title{
Role of Putative Epigenetic Mechanisms in the Intergenerational Transmission of Trauma Effects in "Comfort Women" Survivor Offspring
}

\author{
Seon-Cheol Park ${ }^{\bowtie}$ \\ Department of Psychiatry, Inje University College of Medicine and Haeundae Paik Hospital, Busan, Republic of Korea
}

The article on the intergenerational transmission of trauma effects in the offspring of "comfort women" survivors by Lee et al., ${ }^{1}$ published in the March 2019 issue of Psychiatry Investigation, has yielded important findings. Because the "comfort women" survivors were exposed to extreme trauma, including rape, sexual torture, physical trauma, starvation, death threats, and witnessing of others being tortured and/or killed as Japanese military sexual slaves during the Second World War, all of them had post-traumatic stress disorder (PTSD) throughout their lifetimes and some had complex PTSD. ${ }^{2}$ According to the findings of the study by Lee et al., ${ }^{1}$ among the six offspring of "comfort women" survivors, case A presented depression, panic attack, insomnia, and aggression; case B presented delinquent behavior in high school and anger outbursts; and case $\mathrm{C}$ presented self-blame, suicidal ideation, somatic symptoms, and sleeping problems. Thus, this study provides evidence regarding the intergenerational transmission of trauma effects in the offspring of "comfort women" survivors.

The intergenerational transmission of trauma effects can be invariably explained by the concept of programmed epigenetic modification. Moreover, the diversity in offspring responses to parental trauma may be understood with the help of the gene-environmental interaction. There has been emphasis on the distinction between the inherited effects of intergenerational biological transmission and the non-inherited effects of parental behaviors; however, inherited and non-inherited

Received: April 10, 2019 Accepted: May 1, 2019

$\triangle$ Correspondence: Seon-Cheol Park, MD, PhD

Department of Psychiatry, Inje University Haeundae Paik Hospital, 875 Haeundaero, Haeundae-gu, Busan 48108, Republic of Korea

Tel: +82-51-797-3300, Fax: +82-51-797-0298

E-mail: cogito-ergo-sum@hanmail.net

(c) This is an Open Access article distributed under the terms of the Creative Commons Attribution Non-Commercial License (https://creativecommons.org/licenses/bync/4.0) which permits unrestricted non-commercial use, distribution, and reproduction in any medium, provided the original work is properly cited. effects may be commonly associated with epigenetic modifications. Both, parental sex and PTSD status have been regarded as the differentiating factors of the underlying epigenetic mechanisms for the effects of parental trauma exposure on offspring behaviors. ${ }^{3}$ A study on Holocaust survivors' offspring has reported that higher DNA methylation of the exon $1_{\mathrm{F}}$ promoter of the GR-1 $1_{\mathrm{F}}$ gene (NR3C1) is shown by offspring with only paternal PTSD, while lower GR-1 $1_{\mathrm{F}}$ promoter methylation, associated with greater post-dexamethasone cortisol suppression, is shown by offspring with both maternal and paternal PTSD. Cluster analysis has shown that maternal PTSD is associated with higher levels of depressive symptoms and anxiety, and lower level of perceived emotional health, while paternal PTSD is associated with higher level of childhood trauma and lower level of attachment. ${ }^{4}$ This differential association between parental gender and GR-1 $1_{\mathrm{F}}$ promoter methylation and clinical indicators of offspring may be partly explained by the psychiatric manifestations and their diversity of the "comfort women" survivor offspring. ${ }^{1}$

The "comfort women" survivors' offspring behaviors can be partly understood by the epigenetic modification effects of prenatal maternal trauma on offspring behavior. An animal model studying the epigenetic programming of hypothalamicpituitary-adrenal (HPA) axis, has shown that prenatal stress is associated with the sequential alterations related with the $11 \beta$-hydroxysteroid dehydrogenase type $2(11 \beta$-HSD2) methylation, lower expression of $11 \beta$-HSD2 mRNA and $11 \beta-H S D 2$ activity, and elevated cortisol level in placenta. ${ }^{3}$ It is speculated that this association between prenatal exposure to trauma at an early maternal age and high level of NR3C1 methylation may partly influence the underlying mechanisms of the "comfort women" survivor offspring, since it is reported that the "comfort women" survivors had been forced into the Japanese army at ages ranging from 13 to 26 years. ${ }^{5}$ Moreover, it has been concluded that the fetoplacental interactions can be con- 
trolled by sex of the offspring. It has been reported that higher HPA axis reactivity with lower expression of $11 \beta-H S D 2$ mRNA in placenta is shown by female offspring exposed to prenatal stressors, as compared with male offspring exposed to similar stressors. Thus, the differences in clinical manifestations of case A /C (female) and case B (male) in the findings of Lee et al. ${ }^{1}$ can be partly explained.

The potential epigenetic modifications of preconception maternal trauma on the oocyte and fetoplacental environment have been presumed, while few studies have evaluated their intergenerational effects. It has been reported that maternal age during the Holocaust is an independent influencing factor for urinary cortisol levels and cortisol metabolism in adult offspring, whose mothers were children during the Second World War. ${ }^{3}$ A potential hypothesis for the effects of preconception maternal trauma may be proposed from the personal history of case $\mathrm{C}$ in the findings of Lee et al. ${ }^{1}$ During the pregnancy with case $C$, at bumping into a soldier, her mother had a re-experience and arousal without any additional significant exposures to trauma. Thus, it is speculated that preconception trauma exposure-induced prenatal re-experience and arousal might be associated with the epigenetic modifications in fetoplacental environment.

Though Lee et al. ${ }^{1}$ first reported the intergenerational transmission of trauma effects in "comfort women" survivors' offspring, the study had several limitations. First, the sample size of offspring was small. Second, there was little information about the maternal age during the exposure to extreme trauma, maternal PTSD status, and other parental trauma-related information. Third, the association between maternal trauma exposure and offspring biology and behaviors were not studied in detail. Thus, further studies to overcome these limitations are needed. Moreover, further studies about intergenerational (from F0 to F1) and transgenerational (from F0 to F3 or F4) transmission of trauma effects in offspring of "comfort women" survivor in Korea are needed to evaluate the epigenetic modifications in depth.

\section{Conflicts of Interest}

The author has no potential conflicts of interest to disclose.

\section{ORCID iD}

Seon-Cheol Park https://orcid.org/0000-0003-3691-4624

\section{REFERENCES}

1. Lee J, Kwak YS, Kim YJ, Kim EJ, Park EJ, Shin Y, et al. Transgenerational transmission of trauma: psychiatric evaluation of offspring of former "comfort women," survivors of the Japanese military sexual slavery during World War II. Psychiatry Investig 2019;16:249-253.

2. Lee J, Kwak YS, Kim YJ, Kim EJ, Park EJ, Shin Y, et al. Psychiatric sequelae of former "comfort women," survivors of the Japanese military sexual slavery during World War II. Psychiatry Investig 2018;15:336343.

3. Yehuda R, Lehrner A. Intergenerational transmission of trauma effects: putative role of epigenetic mechanisms. World Psychiatry 2018; 17:243-257.

4. Yehuda R, Daskalakis NP, Lehner A, Desarnaud F, Bader HN, Makotkine I, et al. Influences of maternal and paternal PTSD on epigenetic regulation of glucorticoid receptor gene in Holocaust survivor offspring. Am J Psychiatry 2014;171:872-880.

5. Min SK, Lee CH, Kim JY, Sim EJ. Posttraumatic stress disorder in former “comfort women." Isr J Psychiatry Sci 2011;48:161-169. 